
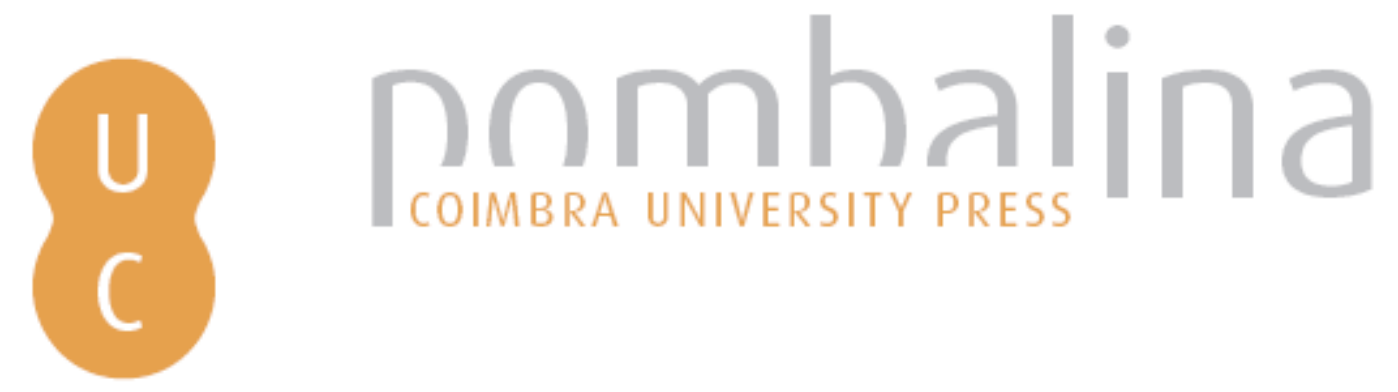

\title{
Corpo ameaçado e stasis na epidemia em Atenas: Tucídides entre o histório e o metafórico (2. 47-54)
}
Autor(es):
Fialho, Maria do Céu
Publicado por: Imprensa da Universidade de Coimbra
URL
persistente:
URI:http://hdl.handle.net/10316.2/45146
DOI:
DOI:https://doi.org/10.14195/978-989-26-1679-7_2
Accessed : $\quad$ 26-Apr-2023 12:25:11

A navegação consulta e descarregamento dos títulos inseridos nas Bibliotecas Digitais UC Digitalis, UC Pombalina e UC Impactum, pressupõem a aceitação plena e sem reservas dos Termos e Condições de Uso destas Bibliotecas Digitais, disponíveis em https://digitalis.uc.pt/pt-pt/termos.

Conforme exposto nos referidos Termos e Condições de Uso, o descarregamento de títulos de acesso restrito requer uma licença válida de autorização devendo o utilizador aceder ao(s) documento(s) a partir de um endereço de IP da instituição detentora da supramencionada licença.

Ao utilizador é apenas permitido o descarregamento para uso pessoal, pelo que o emprego do(s) título(s) descarregado(s) para outro fim, designadamente comercial, carece de autorização do respetivo autor ou editor da obra.

Na medida em que todas as obras da UC Digitalis se encontram protegidas pelo Código do Direito de Autor e Direitos Conexos e demais legislação aplicável, toda a cópia, parcial ou total, deste documento, nos casos em que é legalmente admitida, deverá conter ou fazer-se acompanhar por este aviso.

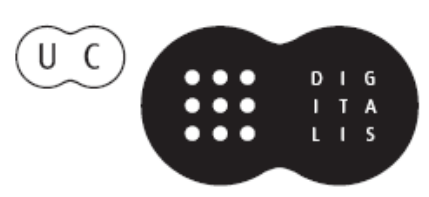



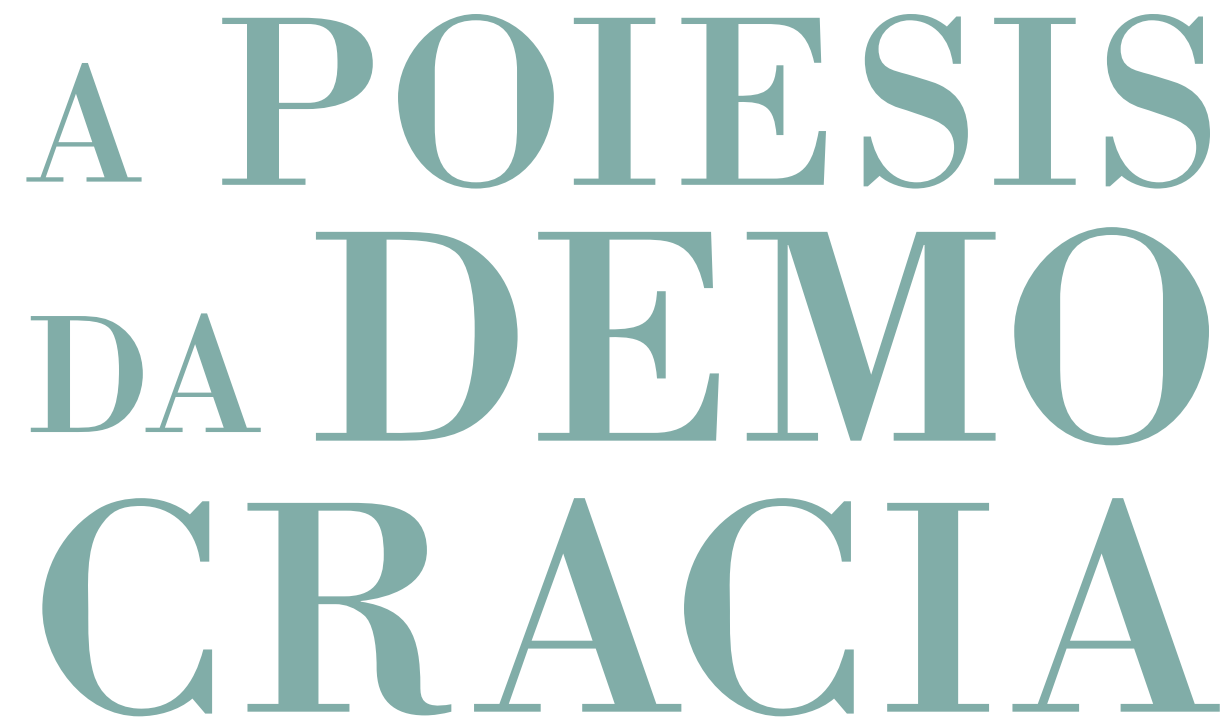

G

Breno Battistin Sebastiani, Delfim Leão,

Lugia Sano, Martinho Soares, Christian Werner

\section{CoimbraCompanions}




\section{Corpo ameaçado e stasis na epidemia em Atenas:}

TUCÍDIDES ENTRE O HISTÓRIO E O METAFÓRICO (2. 47-54)

THREATENED BODY AND STASIS IN ATHENS' EPIDEMY:

THUCYDIDES BETWEEN THE HISTORICAL AND THE METAPHORICAL (2. 47-54)

Maria do Céu Fialho

UNIVERSIDADE DE COIMBRA

ORCID | 0000-0003-2115-9638 


\section{Resumo}

A descrição tucididiana da epidemia ateniense, no segundo ano da Guerra do Peloponeso, foi cuidadosamente concebida pelo seu autor, de modo a conferir-lhe uma dimensão significativa mais ampla. Ela converte-se na imagem de uma doença mais profunda, que afeta mortalmente a polis, que destrói os seus valores e a coesão do tecido social que permite a sobrevivência da democracia. A 'doença' da cidade constitui uma outra face da guerra, mais próxima, mais ameaçadora, que põe em risco a sobrevivência do corpo - do de cada cidadão e do da coletividade. Geradora de stasis que leva, inevitavelmente à metabole, a doença, tal como a guerra, não conduz a uma nova ordem, mas à desagregação da Cidade. Fundamental para a potencialização deste valor quase-alegórico da epidemia é o enquadramento da sua descrição entre dois discursos de Péricles de teor completamente diverso.

\section{Palavras-chave}

Tucídides, Guerra do Peloponeso, epidemia, dimensão metafórica, stasis, metabole, corpo 


\section{Abstract}

The Thucydidean description of the Athenian epidemic in the second year of the Peloponnesian War was carefully conceived by its author in order to give it a larger dimension. It becomes the image of a deeper disease, which mortally affects the polis and destroys its values, as well as the cohesion of the social fabric that allows the survival of democracy. The 'disease' of the city is another aspect of the war, which is closer, more threatening, and endangers the survival of the body of every citizen and of the community. Generator of stasis that inevitably leads to metabole, disease, like war, does not lead to a new order, but to the disintegration of the City. Fundamental to the enhancement of this quasi-allegorical value of the epidemic is the framing of its description between two entirely different discourses of Pericles.

\section{Keywords}

Thucydides, Peloponnesian War, epidemic, metaphorical dimension, stasis, metabole, body 
A modernidade de Tucídides é comprovada pelo facto de, ainda hoje, valer como explicação para as causas da fragmentação política na Hélade a sua minuciosa narrativa e descrição de como, em tempos pré-históricos, foi sendo povoado o território da Península dos Balcãs, na faixa sul, no que viria a ser, futuramente, o território da Hélade continental, e de como esse povoamento, condicionado pelas acessibilidades e características geomorfológicas, determinou o relacionamento entre as cidades gregas e o estatuto relacional ambíguo entre elas.

Essas são as causas constitutivas, por assim dizer, da physis helénica: por um lado as cidades estão marcadas pela autarkeia que caracteriza a polis, com a consequente rivalidade entre as várias póleis, por outro, encontram-se marcadas por um sentimento de pertença a uma civilização comum, com uma língua comum, valores éticos e todo um património religioso, narrativo, político comum.

E Tucídides vai seguir, com a observação atenta de quem presenciou e viveu as consequências a que levou esta falha constitutiva 'arqueológica', a evolução - crescimento, apogeu, sinais de manifestação de uma doença latente, até à discrasia que representa o desequilíbrio funcional dos elementos deste grande corpo político com fraturas na sua coesão global e em cada uma das suas partes - de cada polis. Para tal, o autor segue o processo daquela polis que observa de perto e de dentro, como cidadão: Atenas.

A maturidade de Tucídides corresponde à época da adesão e prevalência do espírito de racionalismo científico. É então, aproximadamente a partir do último quartel do séc. V a. C., que são difundidos resultados da investigação e cálculos matemáticos dos círculos pitagóricos, como as 
tentativas de solução da quadratura do círculo e da duplicação do cubo ${ }^{1}$; por sua vez, em grande parte por influência dos sofistas, velhos dogmas são sujeitos à discussão ${ }^{2}$, para darem lugar ao relativismo científico, à perspetivação múltipla na abordagem de binómios culturais e do conceito de 'verdade', não como 'revelação', mas como consenso ou adequaçãoª .

Por seu turno, os escritos da escola médica hipocrática de Cós suportam uma perspetiva nova sobre a medicina terapêutica e a relação médico-doente: mais do que o recurso imediato a práticas interventivas, a escola hipocrática advoga a atenta observação, por parte do médico, do aparecimento de sintomatologia da doença no paciente e do seu desenvolvimento de modo a que a doença seja, antes de mais, identificada (Prognostikon) ${ }^{4}$. Toda a doença corresponde a uma perturbação da physis e a um desequilíbrio na proporção dos seus quatro humores (Corpus Hipp., Nat. Hom. 2. 16-20). Ao médico compete-lhe, pois, ser o atento servidor (therapeuon) da physis e criar condições (de higiene, por exemplo), ou aplicar então o remédio adequado, para que a physis encontre o meio ajustado para repor o seu equilíbrio.

Esta perspetiva aviva a memória da noção de doença expressa por Alcméon de Crotona (4B-DK) numa metáfora política: à saúde, como isonomia dos vários elementos constitutivos do corpo, opõe-se a doença: prevalência de um só sobre os outros (monarchia).

Em boa verdade, estamos perante uma genuína metodologia da autopsia como condição necessária para a compreensão da natureza humana, do modo como a doença opera e do modo como essa mesma natureza pode

1 A investigação, cujos resultados ora se publicam, foi financiada pelo Projeto da UI\&D 196- Centro de Estudos Clássicos e Humanísticos da Universidade de Coimbra.

O 'Problema de Delos' ou 'Duplicação do cubo' viria a ser solucionado pouco tempo depois da morte de Tucídides por Árquitas de Tarento. Vide Merzbach-Boyer 2011: 63-67.

2 Lembre-se o da prevalência absoluta da physis, que sancionaria um estatismo social aristocrático, e que é então contraposta à eficácia modeladora da paideia, ou o da validade universal da perceção, questionada então pelo modo como cada coisa se deixa perceber, de acordo com as circunstâncias e a entidade que a percebe (Protágoras). Vide Lungbill 1999: 21 sqq.

3 A verdade como 'adequação' virá a ser consagrada por Aristóteles, no seu tratado Sobre a interpretação, que influenciará pensadores cristãos, como Tomás de Aquino. Sobre a transferência do conceito de aletheia de 'revelação' para 'adequação', veja-se Luther 1966.

4 Hornblower 2009: 82-86. 
ser ajudada à recuperação do seu equilíbrio. E se Alcméon de Crotona recorre à metáfora política para explicitar as suas conceções de saúde e doença, o pai da História Política por excelência, Tucídides, vale-se da conceptologia médica da época para clarificar e afinar a sua metodologia historiográfica. Seja a sua obra didática, paradigmática, um tesouro a guardar para sempre (1. 22), todos esses potenciais, referidos, aliás, pelo autor, decorrem dessa dimensão essencial: a da autopsia. O labor de Tucídides consiste, em paralelo com o do médico, na prática da máxima do templo de Delfos - 'conhece-te a ti mesmo' - sendo que esse 'ti mesmo' é, na sua obra, a natureza da Hélade e dos Gregos, com o universo das suas póleis, perspetivado a partir de Atenas - Tucídides é um Ateniense -, e o modo como a génese da Hélade traz em si o germe de grandeza e de fragmentação que se revela, insanavelmente, na maior de todas as guerras. Note-se, contudo, com Hornblower ${ }^{5}$, que esta investigação é mais pautada por um rigor intelectual que por dimensões morais, que a receção de Tucídides tomará.

A universalidade apreendida por Tucídides no processo histórico e no que ele revela do Homem leva-nos a formular a preocupação e intuito tucididiano em termos mais latos: o autor procura, na sua História da Guerra do Peloponeso, apurar, nos homens em ação (ao jeito do que Aristóteles definirá para a tragédiaø), a 'natureza da sua natureza'. Aí reside, porque está marcada por esse universal, a dimensão da sua obra de ktema e de exemplo para a posteridade ${ }^{7}$.

Tucídides não viveu o tempo suficiente para cumprir o seu papel de clínico e apurar se viria ou não a ser genuína a convalescença.

No que diz respeito a Atenas, Tucídides verá, na prolepse que sucede a descrição da peste e a notícia da morte de Péricles, a evolução negativa de uma patologia política que culmina com a futura expedição à Sicília (2. 65.

5 Hornblower 2009: 82 sqq.

6 Aliás, a proximidade do registo tucididiano à leitura trágica da ação humana feita pelo drama seu contemporâneo tem sido apontada em estudos diversos, como abaixo se mencionará.

7 Sintetiza Lungbill 1999: 24: "It is the consistency of human physis, of 'human nature', that Thucydides sees as responsible for the repetitive pattern of human history and it is the grounding of his philosophical system in this belief that gives the work a consistency of philosophy transcending any possible revisions or periods of composition". 
11), e que ocupará os livros 6 e ss., e que é, à partida, definida como um bamartema.

Tem oscilado a perspetiva sobre a maior ou menor dependência de Tucídides da linguagem médica e do modelo médico-doente como inspirador para a sua escrita da história, com recurso a terminologia hipocrática. Hornblower e Rusten, nos respetivos comentários à descrição da epidemia, no livro 2, assumem uma sensata posição intermédia, que constata o facto de a entrada do vocabulário médico na língua culta do tempo ser um dado de facto $^{8}$. De resto, acrescentaria, demonstra-o toda a estrutura do prólogo de Rei Édipo9. Woodman, por seu turno, aponta não só a presença de vocabulário médico que atesta o conhecimento, por parte do autor, dos escritos de medicina, como reconhece na sua narrativa estratégia similar à da narrativa clínica nosológica, sublinhando a importância do 'dia crítico'10. Pelo contrário, Parry nega qualquer cientificismo no passo em apreço ${ }^{11}$.

Ora esta autopsia do processo que vai desde a génese de uma realidade civilizacional, com as suas falhas de origem, ao mais notável edifício cultural e político, patente na Atenas de Péricles, que depois se deixa abater sob as consequências das ditas falhas 'genéticas', agravadas pela cobiça e sede hegemónica das cidades que se envolvem numa guerra sem limites, tem em si, consoante o declara o seu autor, o objetivo de permanecer como um precioso tesouro de memória. É que de um lugar de memória na escrita se trata, e com a sua força de uma peculiar denúncia - tua res agitur - há de fazer valer uma veemente e duradoira eficácia. Esta prevalece através dos tempos, mediante o seu poder de persuasão pela natureza simultaneamente racional e estética do discurso, que eleva a História da Guerra do Peloponeso, em momentos cruciais da sua escrita, ao plano do universal, do potencial, de validade duradoira, ao plano do poético, cuja natureza torna o discurso

8 Hornblower 1997: 316-318; Rusten 1989 comm. ad 2. 47, 2-54, pp. 179-180. Hornblower, no entanto, virá a assumir posteriormente, de forma mais aberta, essa influência 2009: 82 sqq.

9 Fialho 1992: 51-52.

10 Woodman 1988: 38-39.

11 Apud Hornblower 1997: 317. 
incessantemente aberto, de modo a que nele se possam buscar e encontrar novos sentidos, figurados ${ }^{12}$.

Esta peculiar natureza do discurso tucididiano abre portas a um conhecimento, por parte do seu recetor, feito através da experiência estética. Esta transporta o leitor no voo da metáfora e transmite-lhe, como vivência visceral, a globalidade de uma verdade que é de sempre. Resumindo: o poder de persuasão e de exemplo duradoiro na memória decorre também da dimensão poético-retórica desta autopsia ${ }^{13}$.

Quanto aos discursos, postos na boca de personagens históricas, em momentos determinantes, o próprio Tucídides nos diz que eles correspondem ao que potencial e adequadamente teria ou poderia ter sido dito pela figura em causa. É hoje praticamente consensual que tais discursos sejam, essencialmente, construção do autor, ainda que, alguns deles, possam, eventualmente, partir de um núcleo efetivamente pronunciado, mas que não é suscetível de confirmação. Nota Strasburger ${ }^{14}$, conferindo consistência argumentativa à autoria tucididiana dos discursos, que a complexidade da sua construção e a densidade do seu pensamento dificilmente seriam apreensíveis pelo povo; que todos eles apresentam um inconfundível toque de autoria única; que existem inumeráveis referências cruzadas entre eles e, finalmente, que só pode ser ficcional uma oratória de grupo, frequente na obra.

Quanto à descrição-narrativa de fenómenos ou de acontecimentos cruciais, ela pode ser submetida a um processo de metaforização ou condensação expressiva (neste segundo caso lembro o diálogo com os Méliosi5), quer com o objetivo de levar o leitor a sintonizar com o pathos, quer a compreender uma dimensão maior do acontecido e de que esse pathos é sinal.

12 Sobre a ficcionalidade como portadora da verdade histórica, abrindo ao universal, em Tucídides, veja-se a obra de Soares 2017.

13 Hornblower 1997: 317, sublinha as observações de Woodman sobre o forte "rhetorical account" em toda a descrição da epidemia - o que Hornblower apoia, considerando, todavia, uma inegável consistência histórica dos factos, no que toca a epidemia.

14 Starsburger 2009: 191-193.

15 O diálogo, como é sabido, tem como objetivo encenar expressivamente a inocência e fragilidade dos Mélios, por um lado, frente à arbitrariedade e frieza cruel dos Atenienses, sendo ambas as partes representadas como duas totalidades coletivas, que interagem no discurso como dois coros de tragédia. 
Vamos situar-nos na História da Guerra do Peloponeso 2. 47-54, na descrição da epidemia em Atenas, da sua progressão, efeitos imediatos, e mergulhar no que ela diz da guerra.

Não pode, a descrição da epidemia, no seu sentido mais profundo, ser apartada do seu contexto: ela situa-se entre dois discursos 'potenciais' e de natureza completamente diversa, de Péricles. A estreita relação significativa entre estes três passos de referência tem já sido frequentemente notada e comentada ${ }^{16}$.

O discurso que antecede a epidemia, a famosa oração fúnebre (2. 35-46), proferida por Péricles, como epitaphios logos, elogio dos mortos caídos em defesa da pátria, tem, simultaneamente, o carácter de descrição encomiástica dos valores da polis de Atenas e da grandeza e preponderância desta no contexto da Hélade.

Tucídides põe na boca da eminente figura do tempo um elogio ao esforço de gerações, passadas e presentes, em crescendo (2. 36). Denominador comum é a autoctonia dos habitantes da Ática. Os antepassados mais longínquos garantiram a eleutheria de Atenas, que legaram aos seus vindouros (2. 36. 1); quanto aos antepassados mais próximos, há que render-lhes o preito de memória pela esforçada expansão do poderio (arche, 2. 36. 2) da cidade. Quanto à memória dos que caíram na guerra, nada mais adequado do que enaltecer os feitos por palavras e olhar com confiança e orgulho nacional a cidade do presente e os seus cidadãos, pela expansão e consolidação do seu poderio inexpugnável - os gloriosos feitos militares de todos contribuíram para a construção de um império, poderoso, invejável e marcado pela autarkeia ${ }^{17}$.

A coesão de Atenas e o segredo da sua força residem na sua forma de governo: a democracia, que dá iguais oportunidades a todos os cidadãos, mediante a isonomia e consoante os méritos de cada um. A tolerância na vida privada, a justiça e o respeito às leis, seja radicadas no direito positivo

16 E. g. Connor 1984: 63 sqq.; Nichols 2015: 37 sqq.; Shanske 2007: 51-52.

17 Este é, sem dúvida, um discurso que sintoniza com o imperialismo ateniense, sobre o qual Tucídides omite qualquer crítica na boca de Péricles, bem como omite qualquer palavra que justifique moralmente a construção e liderança de um império (e. g. Strasburger, 2009: 295 sqq.) 


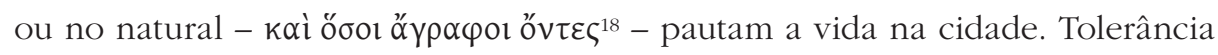
e cosmopolitismo, culto não só do que é bom, mas também do belo, justificam o investimento das riquezas do império.

Naturalmente, estas palavras destinam-se a desculpabilizar a aplicação do tesouro da Liga em prol de Atenas. É tudo isto, segundo o discurso posto na boca de Péricles, que torna Atenas admirável e única, diferente de todas as outras cidades: "Nós cultivamos a beleza com simplicidade e o saber sem fraqueza" (2. 40). Ao valorizar a cidade do presente, como mais gloriosa que a do passado, Péricles lisonjeia os seus potenciais ouvintes, confirmando e fortalecendo esse sentimento de inexpugnabilidade, não sem um toque de demagogia, útil para mais eficazmente conduzir a sua governação ${ }^{19}$.

Finalmente, Péricles centra-se no elogio dos caídos na guerra, ainda que fique bem claro que o enaltecimento maior vai para a comunidade presente dos cidadãos vivos. As suas palavras contêm um eco do famoso epitáfio da autoria de Simónides: o seu túmulo não se circunscreve ao espaço material do túmulo, mas ao mundo inteiro, já que a fama os converteu em tesouros da memória: universalizaram-se, escapando à corrosão do tempo, como os atletas vencedores cantados nos epinícios. Mas, no presente elogio, a dimensão dessa expansão corresponde à dimensão da hegemonia de Atenas.

Que forma de homenagem se impõe por parte dos vivos? Gerar mais filhos, para colmatar a perda e assim "para a nossa cidade trarão duplo

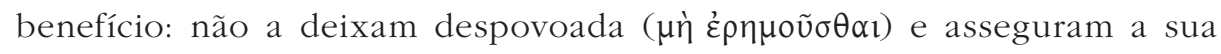
estabilidade" (2. 44).

A descrição das cerimónias fúnebres termina como um fim de etapa neste grande processo nosológico: "Assim acabou o inverno e com ele o primeiro ano desta guerra" (2. 47. 1).

Segue-se o breve relato da invasão da Ática pelos Lacedemónios chefiados por Arquidamo e, seguindo-se, em relato bem mais extenso, a invasão de um outro inimigo: a mortífera epidemia (2. 47-57). A contraposição desse

18 Vide Hornblower 1997: 302-303, comm. ad 2. 37. 2.

19 Nichols 2015: 32-37. Sobre a diversidade de posições sobre a focalização de Péricles por Tucídides, vide Vogt 2009: 223 sqq. 
momento alto de uma Atenas orgulhosa do seu poderio, que se revê no espelho da palavra do seu chefe inquestionável, como Tucídides o quer apresentar, e o dos tempos de crise absoluta, que afeta os próprios fundamentos da cidade, a coesão do seu tecido social e dos valores que o sustentam, através da ameaça à própria sobrevivência do seu corpo (atingindo cada corpo individual), faz-se através de uma mudança brusca, sem transição na narrativa, sublinhada pela oposição de estações do ano e das partículas $\mu \varepsilon^{\prime} \nu$... $\delta \dot{\varepsilon}(2.47 .1-2)$ :

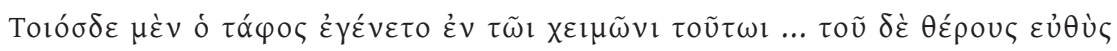

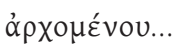

Assim foram as cerimónias fúnebres que decorreram nesse inverno ... e mal começou o verão seguinte...

Sabemos que esta doença, cuja identificação continua a ser um enigma, teve dois surtos, o primeiro no segundo ano da guerra, e o segundo em 429, que vitimou Péricles.

Tucídides, no entanto, omite este facto. Relata a invasão da epidemia de modo concentrado, sem demarcação de tempos nem consequências em indivíduos especificamente identificados. O efeito é óbvio: o autor como que a intemporaliza e torna ainda mais brutal, pois afeta toda a comunidade - aquela comunidade coesa e populosa de que Péricles havia falado.

Esta opção é trabalhada no sentido de conferir mais peso a uma carga simbólico-alegórica da epidemia. Ela vem de fora, como um inimigo que entra pelo porto de mar, sobrelotado de gentes, por via da guerra, e em breve sobe à cidade. Ataca todos, homens comuns e médicos, impotentes para a debelar, pela surpresa e pela agnoia. Ataca o próprio narrador, que sobrevive para contar, de modo a que ela seja, de futuro, reconhecida e diagnosticada (2. 48. 3). Ela representa uma stasis física, mas também social. Tal como na descrição poética da invasão da Dystychia soloniana, percebe-se uma gradação: a doença sobe à cidade. Não respeita nem o estatuto nem a ciência médica (2. 47. 4), já que é altamente contagiosa e 
atinge os médicos na prática do seu ofício e na proximidade aos enfermos. É brutal na sua sintomatologia.

O caminho seguido pela invasão da epidemia corresponde àquele que se foi sobrelotando de população vinda da Ática rural, em obediência à política de Péricles: o porto do Pireu, todo o percurso ao longo das muralhas, até às praças públicas e aos templos dos deuses, onde os refugiados da Ática rural tiveram de procurar abrigo ${ }^{20}$.

Só após a descrição dos seus sintomas, feita com precisão e rigor terminológico de quem domina o vocabulário médico, o narrador 'entra', por assim dizer, na verdadeira natureza da doença: diferente de todas as outras (2. 50), ataca toda a natureza animal e interfere com a ordem social e com os deveres familiares (que há pouco Péricles havia elogiado). Em resumo, salta o muro e entra em casa de cada um. Há cadáveres insepultos, cadáveres atirados para piras de outros cadáveres, doentes por tratar,

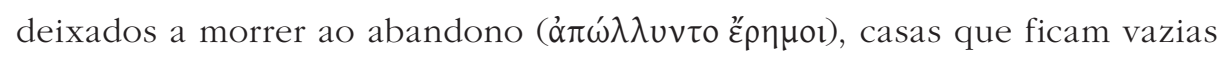

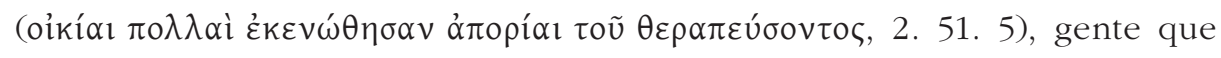
morre em massa, como gado, no espaço público ( - não é este um verdadeiro cenário de campo de batalha? O mestre no tratamento do pathos aproxima, através dele, o leitor em relação à ameaça e sofrimento, à perda de esperança e de sentido da vida individual e comunitária que a epidemia em si representa, bem como na sua dimensão de metáfora da guerra - essa imensa e mortífera ameaça, perturbação ou destruição da vida²1.

Os homens perdem toda a esperança e ânimo de luta contra o flagelo e desistem de lutar contra ele: abandonam-se à sua sorte, descurando deveres e valores, para se entregar ao prazer presente, sem regra nem freio, já que o dia seguinte é incerto e a ameaça da dor e da morte domina toda a cidade (2. 53). O desespero (athymia, 2. 51. 4) apodera-se de todos aqueles que se apercebem que a doença manifestou neles os primeiros sintomas. Morre quem é descurado, morre quem se submete a terapia (2. 51.2) - esta é uma

20 Woodman 1988: 34-35.

21 Parry 1972: 50. 
implacável forma de isonomia: todos são iguais perante as leis da morte. O corpo deixa de ser autarkes (51. 3).

A progressão da doença, no corpo enfermo, é também ela expressiva (2. 49): afetando primeiro a cabeça (sede e fonte da gnome), progride em sentido descendente, lesando de seguida a faringe e a língua (ou seja, os órgãos necessários para produzir o logos que domina a assembleia, que caracteriza a cidade, no discurso de Péricles), até que leva à perda das extremidades (dedos das mãos e dos pés) - ou seja, impossibilita os meios de ação prática, material, e a marcha, que leva o cidadão à praça pública, à guerra, à interação social na polis. Os órgãos genitais são afetados, ficando o sexo e a procriação inviabilizados. Por fim, aquele que sobrevive à epidemia fica afetado por uma perda de memória e pela cegueira (que se pode entender na sua dimensão total, física e de espírito).

Esta súmula sintomatológica condensa um forte efeito de contraste com o epitaphios logos e recebe, ao mesmo tempo, uma outra dimensão significativa mediante a eficácia desse contraste: cada corpo doente consubstancia o corpo da polis, ou a polis como um corpo, perdida a gnome, nessa ânsia hegemónica há pouco enaltecida, para que domine a mania. Afetada fica toda a vida interna da polis, institucional, social, de prática desportiva e de interação pelo corpo.

A falência da vida na cidade democrática existente em palavras é substituída pela isonomia perante a morte. Ninguém sobrevive para reconstruir, com mãos e com olhos que permitam uma visão conjunta e a planificação, ninguém sobrevive para repovoar - o apelo de Péricles à geração de descendência não pode ter eco. Mais ainda: esse pilar da identidade, que é a memória, e que havia sido assinalado por Péricles (ainda que desviada a tónica da memória dos mortos para o orgulho da potencialidade dos vivos), esvai-se, porquanto a perda de memória constitui um dos efeitos da nosos sobre os que a ela logram sobreviver.

Pode dizer-se que a tradicional consciência grega da dimensão antropológica da 'efemeridade', do homem dependente do 'dia' (ephemeros), que convida à moderação, à sophrosyne, e ao culto do esforço e da arete, como estratégia de alcançar uma forma de imortalidade pela memória e pela celebração (de que o epitaphios logos de Péricles constitui o exemplo 
mais próximo), se converte, perante a ameaça total que a epidemia representa para cada cidadão, inclusive ao assumir gestos de solidariedade e de cuidado pelo outro, ao reunir-se com os seus concidadãos nos templos, numa compulsão de esquecimento através do prazer imediato e desenfreado, expressão do desespero e da morte iminente no próprio corpo.

Precisamente, na fase final da descrição o narrador reconhece a estranheza desta doença, que, além do mais, provoca uma metabole na relação dos cidadãos com as leis da cidade e no seu próprio comportamento ético, decorrente da metabole sofrida pelas suas vidas e pela ameaça que paira sobre cada corpo (2. 53. 1): um nosema que leva à anomia - a ameaça da morte e incerteza quanto ao dia seguinte deixa a existência ao sabor da bedone.

Sublinha Orwin"22, com toda a pertinência: "Stasis and plague concur in suggesting that there is no greater political misfortune for human beings than to be freed from the constrain posed by their bodies".

A situação é, de facto, de acordo com a descrição e a sua dimensão imagética, potenciada pelo contexto e pelos contrastes criados por Tucídides entre o retrato da polis no epitaphios logos e na epidemia, de uma profunda stasis, que vai das raízes mais profundas da comunidade, que mergulham na natureza e na paisagem, até ao edifício social, moral e religioso, com todo o seu padrão de valores. Tais contrastes têm já sido assinalados e estudados $^{23}$. Esta stasis parte da experiência de corpo ameaçado, de corpo do outro desagregado, convertido em potencial ameaça de contágio²

Fora das muralhas, Atenas ia perdendo o seu poderio - poderio esse de que Péricles tanto se orgulhara; dentro das muralhas, como se a guerra, sob a forma de nosos, agisse intramuros, esboroava-se todo o edifício democrático e ético, toda a estabilidade de uma cidade que tem futuro

22 1994: 182.

23 Veja-se, por exemplo, o excelente estudo de Nichols 2015: 37 sqq. O mesmo autor apresenta, no primeiro capítulo da sua obra, o 'estado da arte' sobre as diversas interpretações, feitas por autores vários, acerca da posição de Tucídides em relação ao retrato de Péricles e de Atenas no discurso que antecede a epidemia, e que vão desde a tese da adesão total à da crítica implícita à estratégia imperialista do famoso estratego.

24 Orwin 1994: 183 sublinha até que ponto a estabilidade social depende da confiança ou do medo quanto à estabilidade e resposta às necessidades para manutenção de um corpo saudável. A perda da esperança gera uma situação de rutura. 
porque tem cidadãos e casas que garantem a existência de gerações seguintes. Assim havia Péricles, no seu discurso potencial, descrito a paisagem político-social da cidade ideal e democrática que governava.

Aliás, esta preocupação pelo esvaziamento da cidade constitui um topos no sistema democrático. Ela surge na boca do sacerdote suplicante de Rei Édipo (vv. 30-31), surge também como um alerta na boca do Hémon de Antígona diante do tirano: a cidade não é de Creonte nem ele governa uma polis kenandros.

Tem, aliás, sido pertinentemente notada a proximidade da narrativa tucididiana ao modelo trágico, em particular neste tríptico epitaphios logosepidemia-discurso final de Péricles, seguido de menção à sua morte. E tal proximidade levaria à discussão (já havida) sobre o posicionamento de Tucídides quanto à política de Péricles. Assinale-se tão somente, com Woodman ${ }^{25}$, que o contraste acima analisado entre o espelho da cidade, apresentado por Péricles, e a sua desconstrução fatal, agravada pela política de desenraizamento da população rural das suas raízes e casas (e lembremos que Atenas se entendia como autóctone - logo, este desenraizamento soa a política contra naturam), faz ressaltar como que uma hamartia do condutor da cidade. Tal confere à ação e ao desenrolar dos acontecimentos a sua natureza trágica ${ }^{26}$.

A mais profunda dimensão desta doença é atestada, diria, na etapa seguinte: o segundo dos discursos de Péricles. Tucídides joga na ambiguidade, não situando cronologicamente este discurso, já que ele não podia ter sido proferido durante ou após o segundo surto da doença. Perante as vicissitudes, Péricles torna-se o alvo de projeção de desilusões, desencantamentos e acusações, como ocorre quando uma coletividade cai na desgraça. À metabole da cidade, que inclui a mudança de posição quanto ao seu chefe (61.2), corresponde a firmeza deste, que em vão tenta elevar os ânimos e restabelecer a ordem anterior, diria, a physis político-social saudável. Péricles, porém, falha na sua terapia. O seu diagnóstico talvez tivesse sido errado. Em breves

25 Woodman 1988: 35 sqq.

26 Veja-se também Parry 1972: 47-50. 
linhas, Tucídides anuncia (65. 6): "A guerra tinha começado há dois anos e meio, quando Péricles morreu."

Os que se seguiram na chefia da cidade perfilhavam a mesma linha política, porém, faltava-lhes o talento do grande antecessor e sobrava-lhes ambição e arrogância. Estava aberto o caminho dos demagogos, com uma série de hamartemata políticos (65. 11). É agora a vez da introdução específica da linguagem de uma tragédia que já ocorrera antes e que tenderá a expandir-se, globalmente, por um processo de repetição. O caminho conduz, então, ao dia crítico: a expedição à Sicília, fruto de todos os vícios e ambições políticas à solta.

Quanto à democracia ateniense e ao retrato ideal da cidade: bem, em boa verdade, a stasis traduzida na doença, como o outro lado da guerra dentro dos muros da cidade, ameaçando o corpo, a saúde e a vida de cada cidadão e da comunidade de cidadãos, provocou uma metabole que não levou, de facto, a uma nova ordem, mas antes deixou a descoberto a fragilidade de todo o edifício político-social e do poder nele alicerçado. Conclui o narrador: (65. 8):

"Péricles tinha poder devido à sua competência e reputação e era de forma
bem clara totalmente incorruptível; conteve a multidão como quis e guiou-a
mais do que foi guiado por ela... E assim, Atenas, de nome uma democracia,
era na realidade governada pelo seu cidadão mais importante".

Da epidemia como fenómeno real à sua amplificação poética para se converter em símbolo-alegoria do poder corrosivo da guerra, sobre as comunidades e por dentro dos cidadãos, permaneceu uma indelével memória no imaginário ocidental que determinou o tratamento literário de outras epidemias, até à Peste de Camus, grande metáfora da invasão da França pelas forças de Hitler durante a guerra ${ }^{27}$.

27 Hornblower 1997: 316, comm. ad 2. 47. 3-54. 


\section{MARIA DO CÉU FIALHO}

\section{BIBLIOGRAFIA}

Connor, W. R. (1984), Thucydides. Princeton.

Fialho, M. C. (1982), Luz e trevas no teatro de Sófocles. Coimbra.

Hornblower, S. (1997), A commentary on Thucydides. Vol. I: books I-III. Oxford.

Hornblower, S. (2009), "Intellectual Affinities" in: J. S. Rusten (ed.), Oxford Readings in Classical Studies. Thucydides. Oxford, 60-88.

Lungbill, R. D. (1999), Thucydides on War and National Character. Boulder-Colorado.

Luther, W. (1966), Wabrheit, Licht und Erkenntniss in der griechischen Philosophie bis Demokrit. Bonn.

Merzbach, U. C.; Boyer, C. B. (2011, $3^{\text {a }}$ ed.), A History of Mathematics. Foreword by I. Asimov. Hoboken-New Jersey.

Nichols, M. P. (2015), Thucydides and the Pursuit of Freedom. Ithaca-London.

Orwin, C. (1994), The Humanity of Thucydides. Princeton.

Parry, A. (1972), "Thucydides' historical perspective" YCS 47-61.

Rusten, J. (1989, repr. 2001), Thucydides. The Peloponnesian War. Book II, introd. ed., comm. Cambridge.

Shanske, D. (2007), Thucydides and the Philosophical Origins of History. Cambridge.

Soares, M. T. (2017), História e ficção em Paul Ricoeur e Tucídides. Coimbra.

Strasburger, H. (2009), "Thucydides and the Political Self-Portrait of the Athenians" in: J. S. Rusten (ed.), Oxford Readings in Classical Studies. Thucydides. Oxford, 191-219.

Vogt, J. (2009), "The Portrait of Pericles in Thucydides" in: J. S. Rusten (ed.), Oxford Readings in Classical Studies. Thucydides. Oxford, 220-237.

Woodman, A. J. (1988), Rhetoric in Classical Historiography. London-Sydney. 